\title{
Incorporating Health Education in the Curriculum: The Kenyan Experience
}

\author{
Lewis Ngesu ${ }^{1}$, Alice Gichohi ${ }^{2}$ \\ ${ }^{1}$ Associate Professor, University of Nairobi, Kenya \\ ${ }^{2}$ Nursing Officer, Muranga University, Kenya
}

\begin{abstract}
The most recent challenges in health could be tackled by incorporating health education at all levels of learning. This is in tandem with the new global health policy aimed at combating these challenges and developed by the World Health Organization. Health can be created and sustained in schools since most young people are highly vulnerable to particular risks. These include drug and substance abuse, sexually transmitted diseases, poor feeding habits and dangerous relationships that may severe their psychological and mental wellbeing. Schools influence the perception, attitudes, actions and behaviour of young people. This paper seeks to clarify and enforce the need of health education in every level of education. It is based on health promoting social models. The young person is the heart of these models in a dynamic environment. The objectives of this paper include the role of individual and group decisions in sustaining healthy behaviour, reinforcing protective factors and reducing harmful perceptions amongst students.
\end{abstract}

\section{Keyword: Health education, Curriculum}

\section{INTRODUCTION}

It is unanimously known that healthy students are better prepared to learn and succeed in school and life. The current stipulated education policies in our country miss on these vital and simple opportunities to boost health education amongst students. Today's school children are struggling and grappling with lifestyle diseases like obesity, depression and sexually transmitted diseases. They could become the first generation to live shorter and less healthy lives than their parents. The nation must leverage the power of school wellness to boost learning and take advantage of learning opportunities to foster healthy habits that will be of value for a lifetime.
Health education in schools can be advocated through health promoting sessions in schools to promote health literacy amongst students. (McCuaig et al, 2012, Kibui et al 2015). Health literacy should be a core element of the National Curriculum for schools. The World Health Organisation (1998) defines health literacy as the cognitive and social skills which determine the motivation and ability of individuals to gain access to, understand and use information in ways which promote and maintain good health. Health literate individuals are therefore able to make informed health decisions to exert greater control over life events (Shohet \& Renaud, 2006). Health literate individuals are therefore able to make informed health decisions to exert greater control over life events. (Nutbeam (2009 \& 2000) agrees, stating that health literacy promotes and advocates for the health and wellbeing of individuals and society. Given this background, health literacy can be seen as one of the prime resources for positive health and therefore, acquiring it will assist movement toward the healthease (salutogenesis) end of the continuum.

There is limited research done on the influence of health education on health literacy amongst students. This is vis a vis the rise of emerging advocacy of health literacy as a core component in students' curricula. There is limited exploration on the health literacy of students as well as knowledge, attitudes and skills.

Health education is as core a subject like the rest. It should be allocated adequate time, instruction, resources and development like others. It should belong to schools and be recognized as critical to students' education and development. It should have a student centred model for instruction strategy. The teacher should only be a facilitator of the learning 
method. They therefore should utilize the innovative teaching method. It should hence incorporate the community as well for change to be felt. It should have a collaborative approach, integrative and a prerequisite for every school curriculum.

The health education curriculum should be holistic in nature consolidating the physical, mental, social, spiritual and emotional wellbeing of the student. It should highlight key health issues that include community health, family health, mental health, nutrition, substance abuse, and environmental health. Its goals and objectives should be aligned with those of the National health guidelines and standards.

The goals and objectives should be based and supported by existing data which can be qualitative or quantitative in nature. Data used is gathered from parents, guardians, teachers, students, health workers and administrators to prepare the curriculum. It should also be oriented towards the outcomes of student behavior and emphasizing on their skills. This will include accessing information, analyzing influences, interpersonal communication, decision making, self management and advocacy (Nutbeam, $2009 \& 2000$ ).

Bloom's taxonomy of learning domains is of aid if utilized in developing this health education curriculum since it is universal and fathomable. It will include the students' social norms to develop their positive attitudes and values towards health. The teacher takes into consideration that each student has diverse family values that should be respected. The health teacher initiates strategies that help the student to develop positive, health enhancing attitudes and values.

The health education curriculum should also be interdisciplinary whereby the health education teacher liaises with other subject teachers to assist them in including health information and skills in their classes.

The health teacher collaborates with appropriate staff members to make appropriate modifications and accommodations for students.

\section{Health Concerns in Kenya}

According to Maruti et al (2004), Lewis \& Alice (2016) the demand for health education in Kenya has been propagated by increasing knowledge on disease prevention and early treatment. Schools are therefore considered as the best places to implement health education. This is because they are considered as the only society group with the largest mass of a specific age group. They also provide the broadest and deepest channel for passing information. The school is also ideal since it is the second stage of learning from the family setup, Salazar 1995.

There is resurgence of certain disease in the country that are waterborne. These include cholera and dysentery. They are preventable illnesses and yet their prevalence is on the rise. Intestinal worms and enteric fevers are also affecting school children hindering growth and development. Despite access to safe drinking water being a human right, some children can still not access the same. The national coverage of water and sanitation conducted by UNICEF in 2003 averages at $48 \%$ and $42 \%$.

Latrine coverage is also another concern which averaged at 64 school children sharing one toilet as per a study conducted by UNICEF, 2003. The facilities are overstretched and need urgent rehabilitation. Some of the schools lack a pit latrine and bushes are used as toilets. This is worse for the girl child who needs adequate water and proper disposal of sanitary towels due to their physiological needs. Some of the children are from families with poor health seeking behavior and poverty stricken. They therefore cannot afford medical care and hence disease prevention through health education would be crucial (Kelly, 1987).

\section{PROTECTION, PREVENTION EDUCATION MODEL}

Various models have been developed as an effort to enforce health education in various schools across the world. The Swiss government adopted the protection, prevention and education model that consolidates these three aspects. Its main advocacy is health promotion whose purpose is to identify aspirations, satisfy needs, and change or cope with the environment. Any school that supports health education works explicitly on the theme of health promotion at all levels of school life. It will also invest in implementing appropriate measures (Whitehall, 2004).

Protection is one of the targeted themes that aim to create a supportive environment to students with special educational needs. Protection incorporates a safe and friendly environment to the school's 
fraternity which entails adequate security for all, making facilities available like classrooms, playground, and equipment for physical education. It also means that there are competent adults to listen to students to address students' problems, health personnel like a school nurse and teachers trained on health education, counseling and first aid. It also means that the meals given to students are of high quality and their routine of feeding are not ignored. This does not also exclude laws concerning alcohol, drug and substance abuse.

The theme of prevention seeks to promote desirable behavior amongst students and mitigating high-risk behavior. It means developing activities that are centered on a type of behavior or a risk. It includes accidents at home and in school, addictions, food preparation and observing high standards of hygiene. It also means availing information and counseling sessions at all adult levels in the school community and providing condom dispensing machines in an attempt to reduce unwanted pregnancies and lower the prevalence of sexually transmitted diseases.

Education given on prevention corresponds to the knowledge, skills and attitudes amongst students (CDC, 2014).

This model is in tandem with the Ottawa Charter developed during the first conference on health promotion in Canada in November 1986. It delineated the principles of health promotion as "participation, acquisition of self-help skills, focusing on resources, sustainability, an educational focus on diversity (equality of opportunity between sexes and those from different social, ethnic and religious origins)"

It links education and health closely. It demonstrates the usefulness of educational and preventive action in the school environment. Various studies have shown a positive correlation between health behavior and educational success. In conjunction with multiple factors, health is a prerequisite for students' success. Most of these factors are linked to the social environment.

In his research work, Stewart John stresses that a students' effectiveness is determined by having an activity in more than one domain and must encompass all the dimensions of the student's life in school. Some of the determining factors are the school environment, relationships, quality of life and the school climate. This entails a holistic approach that is necessary for the health wellbeing of the student. It equips the student with self-confidence, ability to express emotions, managing stress and risk. This approach is effective and fruit bearing since it includes major aspects of life. These are pedagogical or class based and another broader view that looks at the social, physical and learning environment.

The model also prioritizes various areas in the school environment and amongst students. It looks at the social wellbeing of the school community, effective communication, school structures, team work, conflict management and prevention of violence. The physical wellbeing of the school community is also considered which elaborates more on a balanced diet, eating disorders, physical fitness and activity, relaxation techniques and posture. Others are the psychological wellbeing of the school community that entail self esteem, stress management, suicide prevention, and drug and substance abuse (Shohet \& Renaud, 2006).

If adopted in our curriculum at various levels, this approach and model would help resolve the current challenges. This is because it does not transfer the responsibility of health education to just a single category of staff but it calls upon everyone to play their role. It would also be needful to have clinicians within the educational system to enhance a high level of commitment and avoid dilution of health education. The health workers will also provide technical expertise to benefit the school community. The school should therefore form close links with the nearest health education stakeholders and departmental level health education committees.

The links make the health education programs sustainable since there is input from experts and close follow up.

\section{Conclusion}

Health education should be everyone's concern and shared by many professionals. These include those in the health sector and education too. This will mould children into a culture that is useful and synergetic from all stakeholders. It will build shared ethics and values. This will be over time, with training and support from government organs.

Having children equipped with knowledge and skills essential to support their health helps to combat physical and mental illness. This is associated with a 
sedentary lifestyle, social withdrawal, stress and poor food choices.

(Bates \& Eccles, 2008) It is important to not only prepare students for their tests and standards but to also prepare them for successful lives.

\section{Recommendations}

Students should be made aware of their health and health seeking behavior. This should be done in schools due to the sharing of common age groups and coordination. A study conducted by National Center for Education Statistics (2009) in Washington DC revealed that more than $95 \%$ of adolescents were enrolled in schools and the school has approximately six hours of contact per day with them. There health is directly linked to their academic performance. Schools offer an ideal setting for delivering health promotion strategies that provide students with opportunities to learn and practice healthy behavior.

Schools should adopt strategies that provide opportunities to practice and reinforce healthy behavior. This should be part of a coordinated school health framework with integrated set of planned activities designed to promote the maximal physical, emotional, social and educational development of the students. It should also involve the family and community based on their needs, resources, and standards. It should be coordinated by a multidisciplinary team for it to be effective, sustainable and program quality (Allensworth, 1997). The team should mainly focus on the key issues that include comprehensive health education, school student and employee wellness, mental health and social services, school nutrition services and physical education.

There should also be a school health team in every school that represents the school and community groups. It should work with the school's administration, parents, staff and community to identify and address their health needs. This should be in tandem with school policies stipulated by the school's council. The policies offer guidance on the development of update health activities (Coon, 2001).

It would also be imperative to involve key stakeholders in the development of the policies. These include the school health team, families, nutrition personnel, and the local community. This group will assist in the development, implementation, and monitoring of the health of students. These stakeholders require regular professional development opportunities that enable them to improve current skills and acquire new ones. This should be in collaboration with national professional bodies, institutions of higher learning and health agencies.

The school should also conduct a continuous evaluation of the school health program that assesses the existing health policies, their implementation and effectiveness. The evaluation should also seek to know whether the development, implementation and monitoring of healthy habits is observed. It should also monitor and evaluate the type of communication used to promote healthy behavior amongst members of the school community. All the groups involved should also have their input. Key variables of evaluation include knowledge, attitudes, self confidence, and behavioural intentions. This will minimize loopholes in the system and enhance continuity (American Academy of Pediatrics, 2006).

\section{References}

1. Agnes Kibui, Ruth Mugo, Grace Nyaga, Lewis Ngesu, Mwaniki N. \& Bernard Mwaniki (2015). Health policies in Kenya and the new constitution for vision 2030. International Journal of Scientific Research, and Innovative Technology, 2 (1) pp127-134.

2. American Association for Health Education. (2010). A competency-based framework for health education special- ists - 2010. Whitehall, PA: Author.

3. Centers for Disease Control and Prevention, (2013). Characteristics of effective health education curriculum. Re- trieved from http://www.cdc.gov/healthyyouth/SHER/character istics/index.htm.

4. Centers for Disease Control and Prevention. (2014). Youth Risk Behavior Surveillance Survey. Retrieved from http:// www.cdc.gov/HealthyYouth/yrbs/index.htm.

5. Coalition of National Health Education Organizations. (2011). Code of ethics for the health education profession.

6. National Commission for Health Education Credentialing Inc., Society for Public Health Education, Retrieved from http://www.cnheo.org/ethics.html. 
International Journal of Trend in Scientific Research and Development (IJTSRD) ISSN: 2456-6470

7. Kelly PJ.and Lewis, J.L. (1987). Educational and Health. ICSU, Pergamon.

8. Kinoti,C. N. (2003.) Pupils Health Practices and the Health Education Curriculum in Primary School in Miriga Mieru West Division, Meru Central District Kenya. Published Master's Thesis, Kenyatta University.

9. Lewis Ngesu \& Alice Gichohi (2016). Sexuality Education: Promoting safe sexual behaviour among university students in Kenya. Msingi Journal, 1(2) pp 175-187.

10. McCuaig, L., Coore, S., \& Hay, P. (2012). Reducing dissonance along health education fault lines: Health literacy and the case for efficacious assessment, Asia Pacific Journal of Health, Sport and Physical Education.

11. Nutbeam, D. (2008). The evolving concept of health literacy. Social Science \& Medicine, 67(12), 2072-2078.
12. Sexuality Information and Education Council of the United States. (2004). Guidelines for comprehensive sexuality education: Kindergarten through 12th grade, 3rd Ed. New York, NY.

13. Shohet, L., \& Renaud, L. (2006). Critical analysis on best practices in health literacy. Canadian Journal of Public Health, 97, S10-S13.

14. United Nations Children's Fund (UNICEF) and World Health Organization (WHO) (1988). Prototype Action-Oriented School Health Curriculum for Primary Schools: Teacher's Guide.

15. WHO (1990). Education for Health: A manual for Health Education in Primary Healthcare. Geneva, Switzerland.

16. WHO (2003). Water and Environment Sanitation in School. Report of a workshop held at the Stanley Hotel Nairobi.

17. Young, B. and Durston, S, (1987). Primary Health Education, Longman. United Kingdom. 